\title{
Teaching and learning nutrition assessment: Student perspectives on integrating findings using the A-to-G conceptual framework
}

Catherine Morley, Sarah Arrowsmith, Vanessa Cooze, and Andrea Field

School of Nutrition and Dietetics, Acadia University

\section{Introduction}

This article is a collaboration of three Bachelor of Science in Nutrition (BSN) students (SA, VC, AF) and one professor (CM). The purpose of this article is to inform dietetics educators about the A-to-G conceptual framework used at Acadia University to facilitate learning in the Principles of Nutrition Assessment (PNA) course, and to share student insights on the learning process.

\section{Purpose of the course}

In the PNA course, students learn and practice applying A-to-G nutrition assessment parameters, the first step in the nutrition care process (Writing Group of the Nutrition Care Process/Standardized Language Committee, 2008; Atkins, BasualdoHammond \& Hotson, 2012). Nutrition care planning is covered in subsequent Nutrition and Disease courses. Nutrition assessment has traditionally been based on anthropometric, biochemical, clinical, and dietary (ABCD) parameters (Gibson, 2012; Regina Qu'Appelle Health Region, 2015; Mahan \& Raymond, 2017). Seven additional parameters are covered in the PNA course; $E$ refers to experiences/meanings of eating and eating environments (Morley, 2016; Morley \& Bonnell, 2019); $F$ refers to food access, experiences with food, and connections with family and friends through food and eating (Morley, 2013; Morley \& Accardi, 2013); and G refers to gender (Morley et al., 2019) and genomics (Jenzer \& Sadeghi-Reeves, 2019). The rationale for expanding the PNA parameters beyond $A B C D$ relates to CM's critique of her own (lack of) preparation for practicing as a clinical dietitian, and her observations as a preceptor that more recent graduates likewise did not have preparation in witnessing and interpreting complex nutrition narratives.

\section{CM's perspective}

It is reasonable that people consulting with dietitians expect that the latter, as registered health professionals, are trained and ready to do their jobs. I was not. I describe my early years of working as a clinical dietitian as "flinging the unprepared onto the unsuspecting". Although I had strong preparatory training in assessing $A B C D$ parameters, I had no guidance on how to make sense of a person's story (what I refer to as a nutrition narrative) that emerged while taking a diet history, nor the importance of gaining an understanding of the complex EFG aspects of a person's life to be an effective nutrition counsellor. I had no insight into the dramatic changes in family life and eating rituals and routines that come with changes in health status of someone in the family, and personal and family emotional connections with and through food and eating, particularly when individuals and families are coping with life altering illnesses. I did not know why people cried when explaining why they had wanted to consult with a dietitian, nor what to do when spiritual or religious beliefs were laced throughout nutrition narratives. I did not know if it was acceptable that I cried when witnessing a person's narrative. My training lacked identifying another's wants (what a person is interested in learning about) and needs 
(how they prefer to learn) for nutrition education or counselling (Morley et al., 2016) and how to offer "the kind of help that helps" (Wilber, 1993, p. 255). To enhance my counselling skills, I left clinical practice twice to pursue a Master of Arts in Adult Education (Morley Hauchecorne, Sork \& Barr, 1994) and a PhD in Community Rehabilitation and Disability Studies (Morley, 2002; 2016). As I acquired insights into meanings of eating with changed health status and the importance of honouring people's perspectives, I incorporated these into my approaches to nutrition counselling.

As an educator, I embrace my social responsibility to prepare students for their professional roles, and I recognizethe privilege ofincorporating my understandings of optimizing nutritional care into undergraduate courses. My goal was/is to have students pursuing careers in dietetics arrive at their practicum placements ready to put nutrition care planning knowledge and skills into action. Integrating the EFG parameters is consistent with the Integrated Competencies for Dietetics Education and Practice (ICDEPs) (Partnership for Dietetic Education and Practice, 2014'). I value the concept of transformational learning and incorporate scaffolded learning opportunities into courses.

"Transformational learning is the process of deep, constructive, and meaningful learning that goes beyond simple knowledge acquisition and supports critical ways in which learners consciously make meaning of their lives. It is the kind of learning that results in a fundamental change in our worldview as a consequence of shifting from mindless or unquestioning acceptance of available information to reflective and conscious learning experiences that bring about true emancipation" (Simsek, 2002, n.p.), and,

“... transformational learning often leads to profound changes in our thoughts, feelings, perspectives, beliefs, and behaviors because it is a radical shift of consciousness that permanently alters our way of being in the world" (Simsek, 2002, n.p.).

Scaffolded education:

"refers to a variety of instructional techniques used to move students progressively toward stronger understanding and, ultimately, greater independence in the learning process" (Great Schools Partnership, 2015).

I When developed, dietetics educators applied the 2014 ICDEPs (v. 2). The course outline will change to reflect the 2020 ICDEPs (v. 3)
"Teachers provide successive levels of temporary support that help students reach higher levels of comprehension and skill acquisition that they would not be able to achieve without assistance" (Great Schools Partnership, 2015).

Two conceptual frameworks are used throughout the course, the A-to-G parameters (as above), and the Organizational Framework for Exploring Nutrition Narratives (OFFENN) (Morley, 2016). The OFFENN is "intended to offer insights into the multiplicity and interconnectedness of issues involved in eating and feeding, and to offer practitioners a means to sort through the issues expressed in nutrition narratives that might otherwise appear rambling, confused, or not related to eating" (Morley, 2016, p.40). A scaffolded progressive development learning approach takes place through introduction of the frameworks, and then working collaboratively to apply the frameworks to assess case studies of people of a variety of ages, diagnoses, abilities, and social situations. Students also complete three journalling assignments on weight bias, nutrigenomics, and transgender and gender diverserelated food, nutrition, and eating issues. The final examination consists of students completing two of four case studies, incorporating findings arising from working through both conceptual frameworks.

Students' transformational learning was evident through the final assignment, a reflection on how incorporating EFG parameters affects the outcome of nutrition assessments. Frequently mentioned was the shift from originally thinking that nutrition assessment involved qualitative and quantitative assessments of a person's diet to recognizing how the complex milieux in which people live and how the social, economic, psychological, and hermeneutic aspects of a person's life influence their food intakes and ultimately, their nutritional status. I invited three students to share parts of their final assignments in this article comparing their insights to my intent for the course. I am grateful for their contributions.

\section{Student reflections}

\section{AF's perspective:}

Humans are complex and, unlike many other species, our food has cultural, emotional, and physical significance. However, since food is such a social part of culture, it would be amiss to exclude parameters that contribute to assessing another person's eating experiences and associations. Throughout the PNA course, the connections between the EFG parameters 
became obvious; it is important to consider all of the ways in which a person's food traditions are linked to their identity and eating experiences, and how each of these components affects the others.

As well as consuming nutrients, eating involves tastes, textures, colours, the enjoyment of the ways that these components interact with each other, and sharing the experience with others. Some people are physically unable to eat certain types of foods owing to chewing and swallowing challenges that result from injury, illness, or aging; this is their 'eating experience'. Individuals who are not able to eat will have different associations of nourishment compared to those who can eat. Valuing sensory and social experiences of eating teaches us about the importance of considering the entire person and their experiences in approaches to nutritional care.

Another consideration in nutrition assessment is the impact an individual's social network has on their nutritional intake and eating experiences ( $F$ parameter of family and friends). Eating is associated with social gatherings, traditions, and community, no matter where in the world a person lives. Therefore, social interactions impact whether or not we eat, when we eat, what we eat, and ultimately, our nutrient intakes. Nutrition assessment that incorporates the social factors influencing food intake helps the assessor to recognize barriers to maintaining eating.

Many people will continue to cook what is familiar, perhaps due to family traditions and associated comfort, while others like experimenting with new ingredients and recipes. Additionally, people may avoid or gravitate towards certain foods based on their social group. Other $F$ parameters are food access and food security. Food accessibility completely affects the types of foods to which an individual is exposed, and this affects eating patterns and intakes. For example, people who visit food banks have access to what is available on those shelves, not the same variety available to people who have the means and access to shop at a grocery store or farmers' market. Another example is in northern communities where people rely largely on imported foods; this impacts pricing and accessibility of fresh food. Food access and security are associated with other social determinants of health $(\mathrm{SDOH})$ including income, stress, or education. Assessing food access yields important information that will affect one's approach to nutrition education and counselling.

\section{VC's perspective:}

Stepping into the PNA course, I was oblivious to the contributions of EFG parameters to nutrition assessment. I had been eager to learn about the ABCD parameters and related calculations. In my journal entry on adopting a Health at Every Size (HAES) philosophy, I discussed how I had realized the insufficiency of single anthropometric measurements in assessing a person's nutritional status. HAES and other weight neutral approaches shift the focus from weight management to encourage body acceptance rather than weight loss, support reliance on internal hunger and satiety cues rather than dietary restriction, and promote, intuitive physical activity that is enjoyable rather than structured exercise (Bacon \& Aphramor, 2011). Additionally, the evidence on the relationship or lack thereof between $\mathrm{BMI}$ and longevity was astonishing. Because BMI only weakly predicts longevity, with most studies concluding that people with higher BMIs live as long, if not longer, than people in an 'ideal weight range', I began to question the dominance of $A B C D$ parameters in nutrition assessment. I realized that using $A B C D$ parameters contributes to the stigmatization of individuals based on weight by focusing on the concept that health is determined by body size and composition. Placing individuals in degrading categories and labelling their existence as merely obese, healthy, or underweight further exacerbates the already ever-present weight stigma that exists within today's society. Listening to individual needs, wants, struggles, and identifying how a person's situation relates to the $\mathrm{SDOH}$ through the assessment of EFG parameters has the potential to contribute to health promotion without contributing to weight stigmatization.

The ABCD parameters do not allow for consideration of gender diversity, that is, gender identity beyond a male/female binary. People who identify as transgender or gender diverse ( $T+G D)$ experience physical and chemical changes during the transitioning process that must be included in a nutrition assessment. Incorporating gender identity $(\mathrm{G})$ into nutrition assessment creates conditions for the assessor to gather more in-depth information about the lived experiences of $T+G D$ individuals. The complex social, physical, and mental changes that accompany transitioning relate directly to eating environments (E), and food relationships with family and friends (F). Unfortunately, many people identifying as T+GD do not seek nutrition consultations due to fear of further stigmatization (Public Health Agency of Canada, 2019). 
I also learned about another $\mathrm{G}$ parameter, the relatively new field of nutrigenomics, identifying relationships between nutrients and DNA processing. Consideration of nutrigenomics has the potential, through diet, to influence overall health and chronic disease expression (Dennett, 2017), and to enhance opportunities for individualized recommendations.

Over the PNA course, it became clear that no parameter should stand alone; incorporating findings from all ABCDEFG parameters in assessments accounts for the $\mathrm{SDOH}$ and allows for more individualized approaches to nutrition care. From the knowledge I have gained through the PNA course, I plan to advocate for nonbiased nutrition assessment methods because one's body shape or size, weight, or gender should never be the sole determinant of their health status. We are social beings with complex lives and feelings who deserve respect. Taking a more inclusive approach to nutrition assessment will preserve the human-to-human aspects of nutrition care.

\section{SA's perspective:}

Using the ABCD parameters as the basis for nutrition assessment limits our ability to individualize nutritional recommendations for each person's success. Countless factors influence a person's food intake thus, it would be challenging to gain a sense of what kind of help would be beneficial by assessing only the ABCD parameters. Without the additional EFG parameters, people can be unfairly compared to unattainable standards.

In learning of the EFG parameters, it is understandable that consideration of these parameters may be implied however, through discussing them in class, I was able to build on the perceptions and understandings of others, and to develop an appreciation of the importance of these parameters in nutrition assessment. Knowing the environments (E) in which an individual spends their time and in what environment(s) they eat helps the assessor to develop insights into that person's daily life. The environment is not only the place one eats, it is an indicator of lifestyle and foods available. Whether someone eats most meals at work, home, or other areas (such as in a long-term care facility or hospital) impacts the diversity of choices available and what a person can eat. To avoid giving advice that cannot be followed, it is important to recognize that in these situations some people might not be able to prepare or access certain foods. Also of importance is knowing the individual's associations with eating experiences (E). When they eat, do they experience comfort, joy, pain, guilt, or something else? Knowing about these experiences helps the assessor determine if they need to follow up on issues such as swallowing challenges, gastrointestinal pain, or psychological discomfort. This opens conversations to collaborating to find solutions. It is important to learn if or how a person's changed health status has altered their eating habits so that efforts can be put into addressing obstacles as a means to reduce stress. If these issues are not addressed, the person may not be able to create their new normal because they are experiencing discomfort. They also risk developing negative relationships with food and eating.

Individuality becomes evident when considering nutrigenomics in nutrition assessment. Unfortunately, accessibility to nutrigenomic testing is limited. Awareness of its potential in nutrition assessment serves to emphasize the importance of individualization and prevent applying the same principles and expectation for all.

By the end of the course, it was clear that nutrition assessment must include the EFG parameters. A clientcentered approach is not so unless the complexities of life are considered such as one's environment, eating experiences, connections through food with friends and family, nutrigenomics, and gender.

\section{Student reflections: Summing up}

In PNA, we learned that nutritional status is typically assessed using ABCD parameters. Our view is that using only these parameters limits the perspective of the person conducting the nutrition assessment as there is no accounting for the many factors that influence food intake. Incorporating the EFG parameters promotes respect for diversity. In developing insights into challenges or barriers to achieving one's nutritional goals, we learn not only what a person is eating, also why.

\section{CM's summing up:}

As a novice dietitian, I spent years trying to figure out how to conduct nutrition assessments that honoured what people shared about their distress arising from changes in their eating experiences as a result of illness. Because these were the topics that individuals and families most often talked about during consultations, and because there were no extant books/manuals to inform nutrition counselling on assessing these very 
intimate aspects of a person's relationship with food and eating, this became the focus of my doctoral studies.

In integrating the hermeneutics (layers of meaning of one's experiences) into my approach to nutrition assessment and subsequently, into counselling, I gained a sense of affirmation that I was moving closer to offering the kind of help that helped (per Wilber, 1993). One aspect in particular, the gendered nature (DeVault, 1993) of 'masterminding' food and eating in households that carried on even when women were living with serious illness, resonated with what I had observed in counselling practice. My own positive experiences working in nutritional care using the A-to-G framework and the OFFENN is the reason I included the EFG parameters in the PNA course. I consider teaching at the undergraduate level to carry the responsibility to prepare our students for the vocational aspects of their profession. In reviewing the students' journal entries on adding EFG parameters to ABCD, it was affirmed that my intent for the course was met. I am privileged to work with students who will be our future dietitian colleagues and honoured to have the opportunity to contribute to enhancing nutrition care.

\section{References}

Atkins, M., Basualdo-Hammond C., Hotson B., and Dietitians of Canada. (2010). Canadian perspectives on the Nutrition Care Process model and International Dietetics and Nutrition Terminology. Canadian Journal of Dietetic Practice and Research: 7I (2), el8-20.

Bacon, L., \& Aphramor, L. (20II). Weight science: evaluating the evidence for a paradigm shift. Nutrition journal, 10, 9. https://doi.org/10.1/86/1475-289/-10-9

Dennett, C. (2017). The future of nutrigenomics. Today's Dietitian 19:10, p. 30. https://www.todaysdietitian.com/ newarchives/l017p30.shtml

DeVault, M. L. (1994). Feeding the Family: The Social Organization of Caring as Gendered Work (Women in Culture and Society) (Reprint ed.). University of Chicago Press.

Gibson, R. S. (2005). Principles of Nutritional Assessment (2nd ed.). Oxford University Press.

Hauchecorne, C. M., Barr, S. I., \& Sork, T. J. (1994). Evaluation of nutrition counseling in clinical settings: Do we make a difference? Journal of the American Dietetic Association, 94(4), 437-440. https://doi.org/10.1016/0002-8223(94)90100-7
Jenzer, H. \& Sadeghi-Reeves, L. (2020). Nutrigenomicsassociated impacts of nutrients on genes and enzymes with special consideration of aromatase. Systematic review article. Frontiers in Nutrition, https://doi.org/10.3389/ fnut.2020.00037

Mahan, K., \& Raymond, J. (2017). Krause's food and the nutrition care process (14th ed). Elsevier Publishing

Morley, C. (2002). Women's experiences of eating with changed health status. Doctoral dissertation. University of Calgary.

Morley, C. (2013). "Facilitating learning of nutritional assessment: $A B C D+E F$, and using the Organizational Framework for Exploring Nutrition Narratives (OFFENN)". Canadian Foundation for Dietetic Research Sharing Event, Victoria BC (June). At: http://www.cfdr.ca/abstracts.html $(2013 ; 24)$.

Morley, C. (2016). Development and Use of The Organizational Framework For Exploring Nutrition Narratives. Critical Dietetics, 3(2),32-42.https://doi.org/10.32920/cd.v3i2.1008

Morley, C., \& Bonnell, H. (2019). Phenomenology and IBD: Living with and studying eating with inflammatory bowel disease. Critical Dietetics, 4(2), 63-67. https://doi. org/10.32920/cd.v4i2.1324

Morley, C. \& Accardi A. (2013). "The Organizational Framework for Exploring Nutrition Narratives (OFFENN) as a resource to prepare dietetics students and interns for client-centred nutrition counselling". Canadian Foundation for Dietetic Research Sharing Event, Victoria BC (June). At: http:// www.cfdr.ca/abstracts.html (2013:13).

Morley, C., MacLellan, D., Traviss, K., \& Cividin, T. (2016). An Evidence-based Approach to Developing the Collaborative, Client-Centred Nutrition Education (3CNE) Framework and Practice Points. Canadian Journal of Dietetic Practice and Research, 77(2), 78-83. https://doi.org//0.3148/ cjdpr-2015-048

Morley, C., Monster, S., Bonnell, H., Goodridge, L., \& Falkeisen, A. (2019). Transgender and gender diversity nutrition, food, and eating research: Our origin story. Journal of Critical Dietetics, 4(2); 58-62.

Partnership for Dietetic Education and Practice. (20/4). Accreditation standards for dietetic education programs in Canada. Toronto ON: Dietitians of Canada.

Public Health Agency of Canada. (2019). Addressing stigma: Toward a more inclusive health system. Government of Canada. https://www.canada.ca/en/public-health/corporate/ publications/chief-public-health-officer-reports-statepublic-health-canada/addressing-stigma-toward-moreinclusive-health-system.html - a4

Regina Qu'Appelle Health Region Clinical Nutrition Services. (2015). Regina Qu'Appelle Health Region - Dietitian Handbook. 
Scaffolding. Great Schools Partnership. (2015). The glossary of educational reform. At: https://www.edglossary.org/ scaffolding/

Simsek, A. (2012) Transformational Learning. In: Seel N.M. (eds) Encyclopedia of the Sciences of Learning. Boston MA: Springer. https://doi.org/10.1007/978-1-4419-1428-6_373

Wilber, K. (1993). Grace and grit: Spirituality and healing in the life and death of Treya Killam Wilber. Boston, MA: Shambhala Press.

Writing Group of the Nutrition Care Process/Standardized Language Committee. (2008). Nutrition care process and model part I: the 2008 update. Journal of the American Dietetic Association, 108(7): 1113-17.

\section{Author Bios}

(Cath)erine Morley is Acting Director and Associate Professor, School of Nutrition and Dietetics, Acadia University, Wolfville NS and Adjunct Professor, Applied Human Nutrition, Mount Saint Vincent University, Halifax, NS. Prior to joining Acadia University, she worked for over 20 years in cancer care, then as a consultant in nutrition program development and evaluation. Cath's research interests are in how the experiences of eating and family relationships related to food/eating change with illness and aging, what these experiences mean for nutrition counselling, innovations in dietetics education, practice and research, including the integration of critical social theory, art-based approaches, and transinclusivity/ gender diversity.

Sarah Arrowsmith BSN (2022) is active in her community, taking part in organizations including Canada's Atlantic Foodservice Partners, the Acadia Medical Campus Response Team, and the Acadia Children's Health and Nutritional Growth Experience. Sarah is inspired by her experience working as an administrative assistant in healthcare to work in dietetics. She values approaching nutritional care from a HAES perspective to make it more inclusive and accessible to all.

Vanessa Cooze BSN (202I) is from Newfoundland and Labrador. As a prospective dietetic practicum student, Vanessa's research interests include nutritional management of gastrointestinal disease, disordered eating behaviours, and client-centered nutrition care.

Andrea Field BSN (2022) developed an interest in critical dietetics while taking the Principles of Nutrition Assessment course in her second year and has enjoyed building on this knowledge in other university courses. Andrea's goal is to focus on maternal and infant health. 